\title{
Hasta ve Bebek İzleme ve Kontrol Sistemi (HBIKSS)
}

\author{
Ahmet BÖBREK ${ }^{1 *}$, İsmail KIRBAŞ², Kamil ÖZCAN \\ ${ }^{1}$ Mehmet Akif Ersoy Üniversitesi, Teknik Bilimler Meslek Yüksekokulu, Burdur \\ ${ }^{2}$ Mehmet Akif Ersoy Üniversitesi, Mühendislik Mimarlık Fakültesi, Burdur \\ ${ }^{3}$ Mehmet Akif Ersoy Üniversitesi, Gölhisar Meslek Yüksekokulu, Burdur
}

Geliş Tarihi (Received): 02.10.2017, Kabul Tarihi (Accepted): 27.11.2017

$\square$ Sorumlu Yazar (Corresponding author*): abobrek@mehmetakif.edu.tr

(C) +902482134574 成 +902482134598

$\overline{O ̈ Z}$

Günümüzde kablosuz iletişim teknolojilerinin gelişmesiyle birlikte yaşam standartlarının artıııması amacıyla pek çok donanım geliştirilmiştir. Geliştirilen bu donanımlar aynı zamanda internet ağının gelişmesi sayesinde nesnelerin interneti kapsamında da günlük hayatımıza girebilmektedir. Yapılmış olan çalışmada da hareket kabiliyeti kısıtlı olan bebekler ve yatan hastaların sıcaklık ve alt değiştirme gereklilik durumunun takip edilmesi amacıyla kablosuz haberleşebilen bir sistem geliştirilmiştir. Alt değişiminin zamanında yapılmaması diaper dermatit (pişik), mantar oluşumu gibi birçok rahatsızlığa da neden olabilmektedir. Özellikle yatan hastalarda alt ıslaklığının çok sık kontrol edilmesi hastayı rahatsız edebilmektedir. Özellikle yaşıı hastalarda çok sık kontrol hastayı duygusal olarak etkilemektedir. Gerçekleştirilmiş olan sistem ile bakım yapan kişi mobil cihazından veya oda içerisindeki duvar ünitesinden sıcaklık ve alt ıslaklık durumunun takibini yapabilmektedir. Sistem ani ateş yükselmesi görülen hastalıklarda alarm seviyeleri ile hasta sahibini de uyarabilmektedir. İlave olarak çocukların çiş alışkanlığı edinme problemlerinde (enürezis tedavisi) kullanılabilecek şekilde gerçekleştirilmiştir.

Anahtar Kelimeler: Alt Islatma, Uzaktan İzleme ve Kontrol, Kablosuz Haberleşme, Arduino, Nem ve Sıcaklık Ölçümü

\section{Developing a Wifi / Bluetooth Based Patient and Baby Monitoring Application}

\begin{abstract}
Many hardware devices have been developed aiming enhancement of life standards together with advancements in wireless communication technologies today. These developed hardware devices have been also becoming useful tools in our daily life under the internet of things concept by courtesy of high development of the internet network. In the study done, a system with the ability to do wireless communication was developed with the aim of monitoring temperature change and diaper changing-necessity condition of low-mobility infants and inpatients. Late change of diaper may cause various diseases like diaper dermatitis and fungi formations. Also, often checks of underpad may disturb inpatients. Especially often checks of older inpatients may influence them emotionally. Through the realized system, the nurse can monitor temperature and moisture condition from a mobile device or a wall unit inside the room. The system also can warn the nurse through some alarm levels for fast temperature rising. In addition, the system was developed such that it can be used for utilizing in enuresis treatments of children.
\end{abstract}

Keywords: Bedwetting, Remote Monitoring and Control, Wireless Communication, Arduino, Moisture and Temperature Measurement 


\section{Giriş}

Günümüzde teknolojinin gelişmesiyle hayatın her alanında yaşam konforunu artıracak çözümler aranmaktadır. Eski zamanlarda manuel yapılan birçok faaliyetin otomatik olarak gerçekleştirilmesi hayata daha çok zaman ayırmamızı da sağlamaktadır. Yapılmış olan çalışmada iki temel hedef gözetilmiştir. Illki bebeklerde ve yatan hastalarda cildin tahrip olmasına ve birçok cilt hastalığına neden olan idrar ve dışkının ciltle temas süresini azaltmak, ikincisi bakım yapan kişilerin işlerini kolaylaştırmaktır. Bunun yanında hastaların yaşına göre psikolojik olarak etkilenmelerini azaltmak gibi ilave faydaları da olabilir. Bu kısım sosyal bilimlerin araştırma konusu olabilir. Yapılan araştırmalarda cilt ile idrar ve gaitanın uzun süre teması nedeniyle cilt rahatsızlıklarının meydana geldiği temas süresine göre mantar oluşumuna sebep olabileceği, iltihaplanmaların meydana gelebileceği belirtilmiştir. En fazla görülen rahatsızlık halk arasında pişik diye bilinen diaper dermatittir. Hastalık oluşumunun engellenmesi veya oluşmuş olan hastalığın tedavisi için yapılması gereken temas süresini azaltmak yani alt değişiminin zamanında yapılmasıdır (Eriş ve ark.,2010; Önder ve ark.,2007). Diaper dermatit sadece bebeklik ve çocukluk döneminde değil tüm yaşalarda rastlanabilecek bir rahatsızlıktır.Yoğun bakım ünitelerinde görülen cilt hastalıklarının da \% 25’i diaper dermatittir (Kara ve ark.,2015). Bahsedilen rahatsızlıkların oluşmaması için çözülmesi gereken temel problem alt değişim zamanının doğru tespiti ve bakıcıya bildirilmesidir. Literatürde alt değişim zamanının tespitinden çok çocuklarda görülen alta kaçırma rahatsızlığının giderilmesine yönelik çalışmalar mevcuttur. Çiş esnasında alarm vererek çocuğu uyaran cihazlar geliştirilmiștir (Atar ve Sancaktutar, 2011). Geliştirilen ilk örnek, bakıma intiyaç duyan çocuklar ve yetişkinlerin için kullanılabilecektir.

Hasta ve Bebek İzleme ve Kontrol Sistemi (HBIKS) vücut sıcaklığı ve alt ıslaklığı takibini gerçekleştirmektedir. Ölçtüğü değerleri bakıcı kişiye ve internet ortamına aktarmaktadır. Hastaların uzaktan izlenmesi, yapıımış olan pek çok çalışmaya konu olmuştur. Uzak merkezle arasında tıbbi amaçlarla fizyolojik işaretlerin aktarımı teletıp (telemedicine) olarak isimlendirilir(Kyriacou ve ark.,2001).Vücut sıcaklığı takibi yapabilmesi açısından teletıbbın alanına girmektedir. Özellikle yaşamsal işaretler olarak kabul edilen nabız solunum sıklığı, kan basıncı, vücut sıcaklığı, oksijen satürasyonu yüzdesi gibi işaretlerin takibi ön plana çıkmıştır. Çalışmalar ile ilgili örnekler Tablo 1'de gösterilmiştir.

Tablo 1. Örnek Teletıp Uygulamaları

\begin{tabular}{|c|c|c|c|c|}
\hline Çalışmayı Yapan & Aktarılan İşaret & $\begin{array}{c}\text { Kullanılan Haberleşme } \\
\text { Yöntemi }\end{array}$ & $\begin{array}{l}\text { Düğüm } \\
\text { Sayısı }\end{array}$ & Görsel Program \\
\hline (Eriş ve ark.,2010) & $\begin{array}{l}\text { Oksijen saturasyonu, nabız } \\
\text { ve vücut sıcaklığı }\end{array}$ & RF(433 MHz) standardı & 3 & LabVIEW \\
\hline $\begin{array}{l}\text { (Navarro ve } \\
\text { ark.,2005) }\end{array}$ & $\begin{array}{c}\text { ECG, Kan basıncı, Oksijen } \\
\text { saturasyonu }\end{array}$ & UMTS, IPv4 & 3 & Özel Yazılım \\
\hline (Moron ve ark.,2005) & Oksijen saturasyonu & Bluetooth/Gprs/Wi-fi & 3 & Özel Yazılım \\
\hline $\begin{array}{l}\text { (Figueredo ve Dias, } \\
\text { 2004) }\end{array}$ & $\begin{array}{l}\text { ECG, Nabız, Kan basıncı, } \\
\text { Oksijen saturasyonu, vücut } \\
\text { sıcaklığı, solunum değerleri }\end{array}$ & $\begin{array}{l}\text { RS232 seri haberleşme, } \\
\text { UMTS,TCP/IP }\end{array}$ & 3 & Özel Yazılım \\
\hline (Chien ve ark.,2005) & ECG, EMG & $\mathrm{RF}(433 \mathrm{MHz})$ standardı & 3 & Özel Yazılım \\
\hline $\begin{array}{c}\text { (Cosmanescu ve ark., } \\
\text { 2006) }\end{array}$ & ECG, EMG & Bluetooth & 2 & HSPICE \\
\hline (Rezai ve ark.,2007) & ECG & Bluetooth & 2 & LabVIEW \\
\hline $\begin{array}{c}\text { (Oweis ve } \\
\text { Barhoum,2007) }\end{array}$ & ECG & $\mathrm{RF}(433 \mathrm{MHz})$ standardı & 2 & MATLAB \\
\hline (Toral ve ark.,2007) & $\begin{array}{l}\text { Oksijen saturasyonu, nabız } \\
\text { ve vücut sıcaklığı }\end{array}$ & RS-232 & 1 & LabVIEW \\
\hline $\begin{array}{c}\text { (Kumar ve } \\
\text { Rahman,2006) }\end{array}$ & $\begin{array}{l}\text { Oksijen saturasyonu, nabız } \\
\text { ve vücut sıcaklı̆̆ı }\end{array}$ & $\mathrm{RF}(433 \mathrm{MHz})$ standardı & 3 & LabVIEW \\
\hline (Çetin ve ark.,2012) & Vücut sıcaklığı, Nabız & Wi-fi/İnternet & 3 & MATLAB, Özel Yazılım \\
\hline (Kirbaş ve ark.,2010) & Sıcaklık, Nem & isMOTE KAA & 3 & Özel Yazılım \\
\hline (Işık ve ark.,2013) & Solunum fonksiyonu & Bluetooth/3G/Wi-Fi/RF & 2 & Özel Yazılım \\
\hline (Işık ve ark.,2010) & Hasta ile ilgili sağlık anketi & $3 \mathrm{G} / 4 \mathrm{G}$ & 1 & Özel Yazılım \\
\hline
\end{tabular}


Sıcaklık izleme daha önce pek çok çalışmaya konu olmuştur. Bu çalışmadaki özgünlüğü sağlayan alt değişim zamanının tespit edilmesidir. HBIKKS' in kullanımı ile;

- Hasta ve bebeklerde cilt rahatsızlıklarının oluşumu engellenebilir.

- Oluşmuş olan hastalığın tedavi süresi kısaltılabilir.

- Özellikle yaşlı hastaların alt kontrolleri manuel olarak yapılmaz. Hastanın psikolojik olarak rahatsız edilerek utandırılması engellenir.

- Vücut sıcaklığı takip edilebilir. Ani ateş yükselmesi görülen rahatsızlıklar için alarm seviyeleri oluşturularak sesli, ı̧ıklı ve titreşimli alarm verilmesi sağlanabilir.

- Vücut sıcaklık değişimleri düzenli olarak raporlanarak hekimler için bilgi verici veri oluşturulabilir.

\section{MATERYAL VE YÖNTEM}

\section{Sistemin Genel Yapısı}

Bebeklerde ve yatan hastalarda vücut sıcaklığı ve alt ıslaklığının uzaktan takibinin yapılabilmesi için bir ilk örnek geliştirilmiştir Sistem üç ana kısımdan oluşturulmuştur;

a) Sıcaklık ve alt ıslaklık ölçümünün yapılacağı hasta veya bebek üzerine yerleştirilecek olan mobil ölçüm ünitesi.

b) Ölçümü yapan mobil cihazın, ölçüm değerlerini ileteceği oda ünitesi.

c) Oda ünitesi ile kablosuz haberleşme yeteneğine sahip mobil takip ünitesi.

Hasta ve Bebek İzleme ve Kontrol Sisteminin (HBIKS) genel yapısı Şekil 1'de gösterilmiştir.

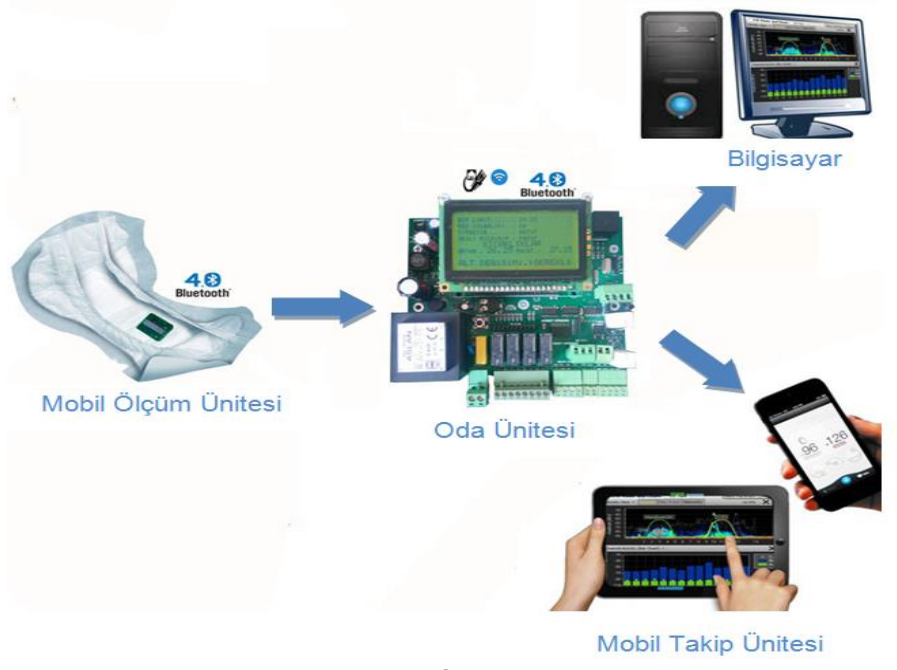

Şekil 1. HBIKKS Genel Yapısı

\section{İlk Örnek Donanımı}

Illk örnek donanımı üç kısımdan oluşmaktadır. Sistem tasarımında değerlendirilen özelliklerin bazıları Tablo 2'de belirtilmiştir.

Tercih edilen bluetooth haberleşme protokolünde tek noktayla veya birçok noktayla aynı anda iletişim kurulabilir. Haberleşmede kullanılan kanalların iki veya daha fazla cihaz tarafından paylaşıldığı ağa piconet denilmektedir. Piconette cihazlardan biri "master" diğerleri "slave" olarak görev yapar ve aynı ağda 7 cihaz aktif iletişim sağlayabilir. Bu sırada ağa bağlı diğer cihazlar park modunda bekleyebilir(Ertürk ve Filiz,2007). Modüllerin eşleştirmesinde donanım kimlikleri (MAC ID) ve AT komutları kullanılmaktadır. Bluetooth modül ile mikrodenetleyiciler kendi aralarında seri haberleşme yapmaktadır.

\section{Mobil Ölçüm Ünitesinin Donanımı}

Kullanım kolaylığı ve ergonomi açısından $31 \times 31 \times 12 \mathrm{~mm}$ ebatlarında üretilmiştir. BLE 4.0 standardında haberleşerek oda ünitesine sıcaklık ve ıslaklık durumunu iletebilmektedir. Ünite ölçüm yaparken mikrodenetleyici çip üzerine yazılan bir yazılım ile analog elektriksel bilgileri dijital sinyallere dönüştürmektedir. Sıcaklık ölçümünde negatif katsayılı direnç (NTC) kullanılmıştır. Malzemenin direnci sıcaklık ile ters orantılı olarak değişmektedir. Ölçüm sırasındaki sinyal değişimleri Labview programıla izlenerek sistemin tepkisi değerlendirilmiştir. Örnek sinyal görüntüsü Şekil 2'de gösterilmiştir.

Program aldığımız veriyi excel programına da aktarabilmektedir. Şekil 3'te cihazlar tarafından elde edilen verinin excel programındaki ekran görüntüsü gösterilmiştir. 
Tablo 2. Tasarım Ölçütleri

\begin{tabular}{|c|c|}
\hline Aranılan Özellik & Değerlendirme \\
\hline 10 metreye kadar iletişim kurabilme & \multirow{4}{*}{$\begin{array}{l}\text { BLE } 4.0 \text { bluetooth modül seçilmiştir. } \\
\text { (6 kByte/saniye iletim hızı } \\
\text { Uyku modunda } 0,4-1,5 \mathrm{~mA} \\
\text { Aktif modda } 8.5 \mathrm{~mA} \text { akım intiyacı) }\end{array}$} \\
\hline Düşük güç tüketimi & \\
\hline İnsan sağlığına zarar vermeme & \\
\hline Yeterli iletim hızı & \\
\hline Analog/Dijital Dönüştürücü & \multirow{3}{*}{ Atmega 328 mikrodenetleyici seçilmiştir. } \\
\hline Düşük Güç Tüketimi & \\
\hline Esnek Programlama İmkânı & \\
\hline Az yer kaplama & 3adet 31x31x0.6 mm pcb tasarlanmıştır. \\
\hline Kolay şarj edilebilme & Li-Po 3,7 V 120 mA batarya tercih edilmiştir. \\
\hline Kablosuz/kablolu haberleşebilme & \multirow{3}{*}{$\begin{array}{l}\text { ENC28J60 ethernet ve HLK-RM04 UART WI-FI modül do- } \\
\text { nanımı eklenmiştir. }\end{array}$} \\
\hline Geniş kapsama alanı & \\
\hline $\begin{array}{l}\text { İnternet üzerinden görüntülene- } \\
\text { bilme }\end{array}$ & \\
\hline
\end{tabular}

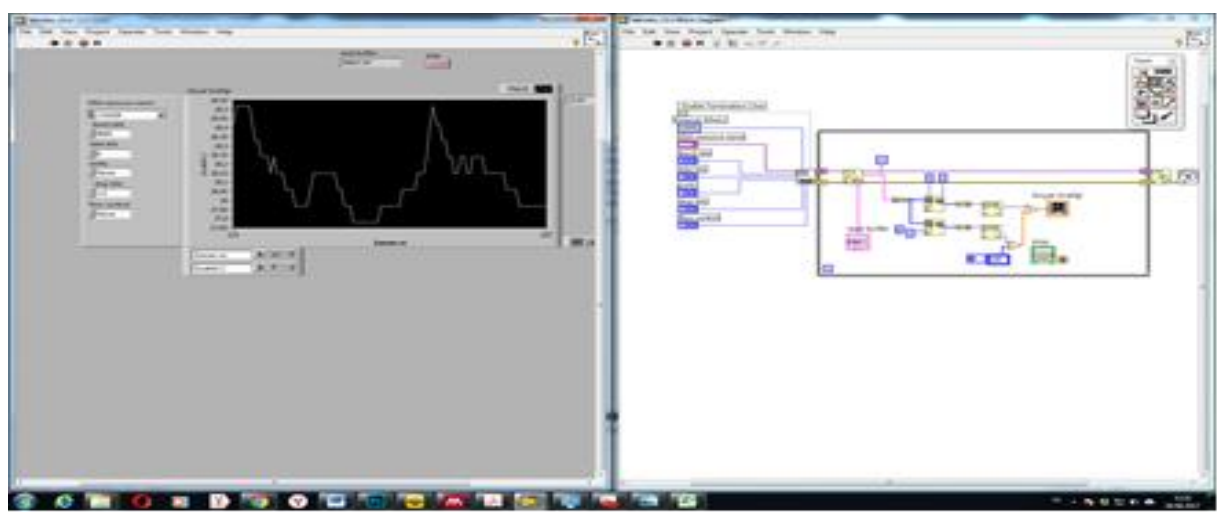

Şekil 2. LabView NTC Ölçüm Grafiği

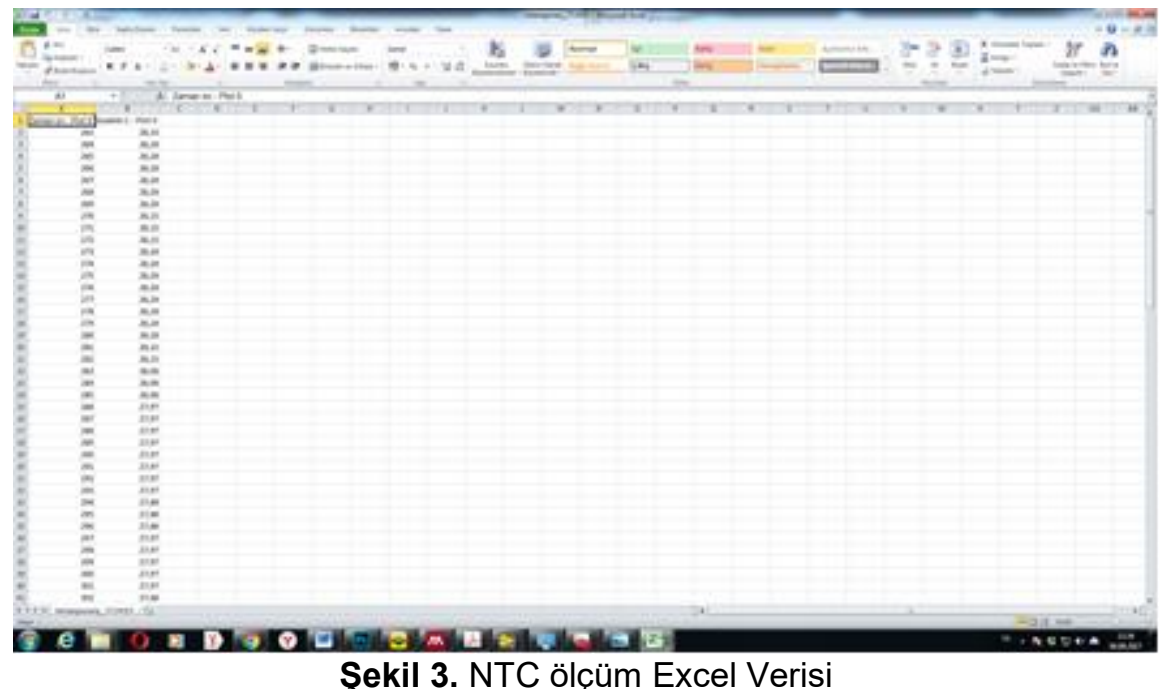

Alt ıslaklık ölçümü için desenli çizilmiş bakır yollar arası oluşacak direnç üzerinden ölçüm sağlanmaktadır. Ölçümün yapılmasında gerilim bölücü bir devre kullanılarak okunan gerilim değerlerinin 10 bit ADC(Analog Digital Converter) ile okunması sağlanmıştır. ADC 0-1023 arası bir değer vermektedir. Islaklık algılayıcı bakır devre yoluna seri bağlanacak direncin değerinin tespiti için üç farklı direnç değeri kullanılarak testler yapılmıştır. $2.2 \mathrm{k} \Omega$ ' luk direnç için ölçüm grafiği Şekil 4, 22k $\Omega$ ' luk direnç için ölçüm grafiği Şekil 5, 4.7M $\Omega$ ' luk direnç için ölçüm grafiği de Şekil 6'da gösterilmiştir. Test esnasında devre yolunun nemlenmesi sağlanmış ve ADC den alınan değerler gözlenmiştir. 


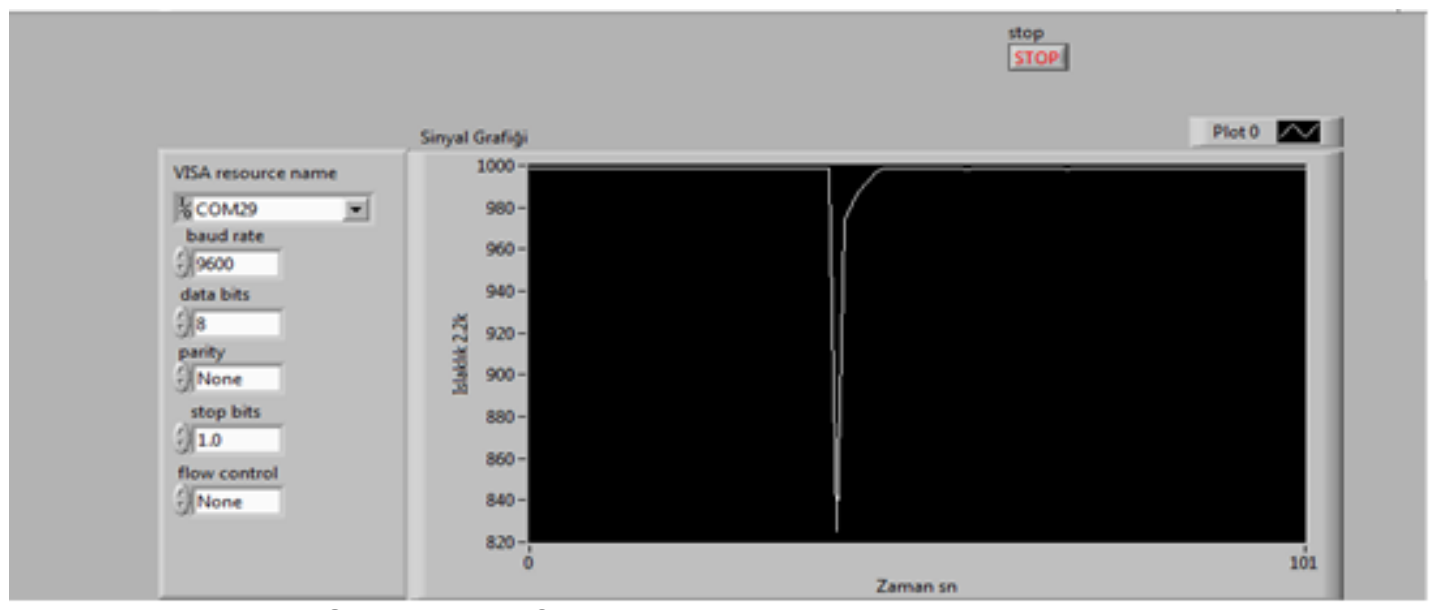

Şekil 4. 2,2 k $\Omega$ ' luk gerilim bölücü ile ıslaklık okuma

Farklı değerlerdeki üç direnç ile yapılan gözlemde 2,2 $\mathrm{k} \Omega$ ' luk direncin salınımının daha az olduğu tespit edilmiştir. Mobil ölçüm ünitesinde gerilim bölücü devre seri direnci olarak 2,2 k $\Omega$ ' luk direnç kullanılmıştır. Eşik seviyelerinin tespitinde sinyalin salınım eğrisi kullanılmıştır.

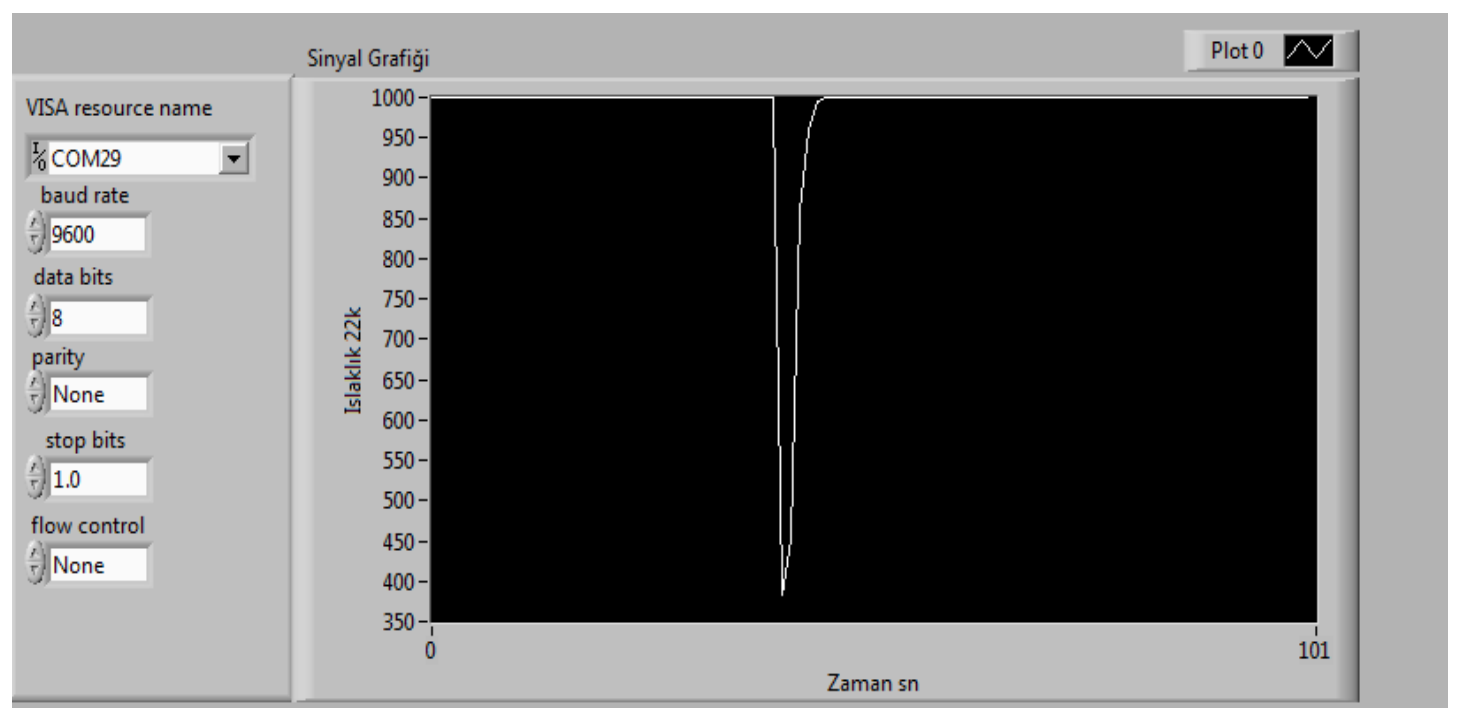

Şekil 5. 22 k $\Omega$ ' luk gerilim bölücü ile ıslaklık okuma 


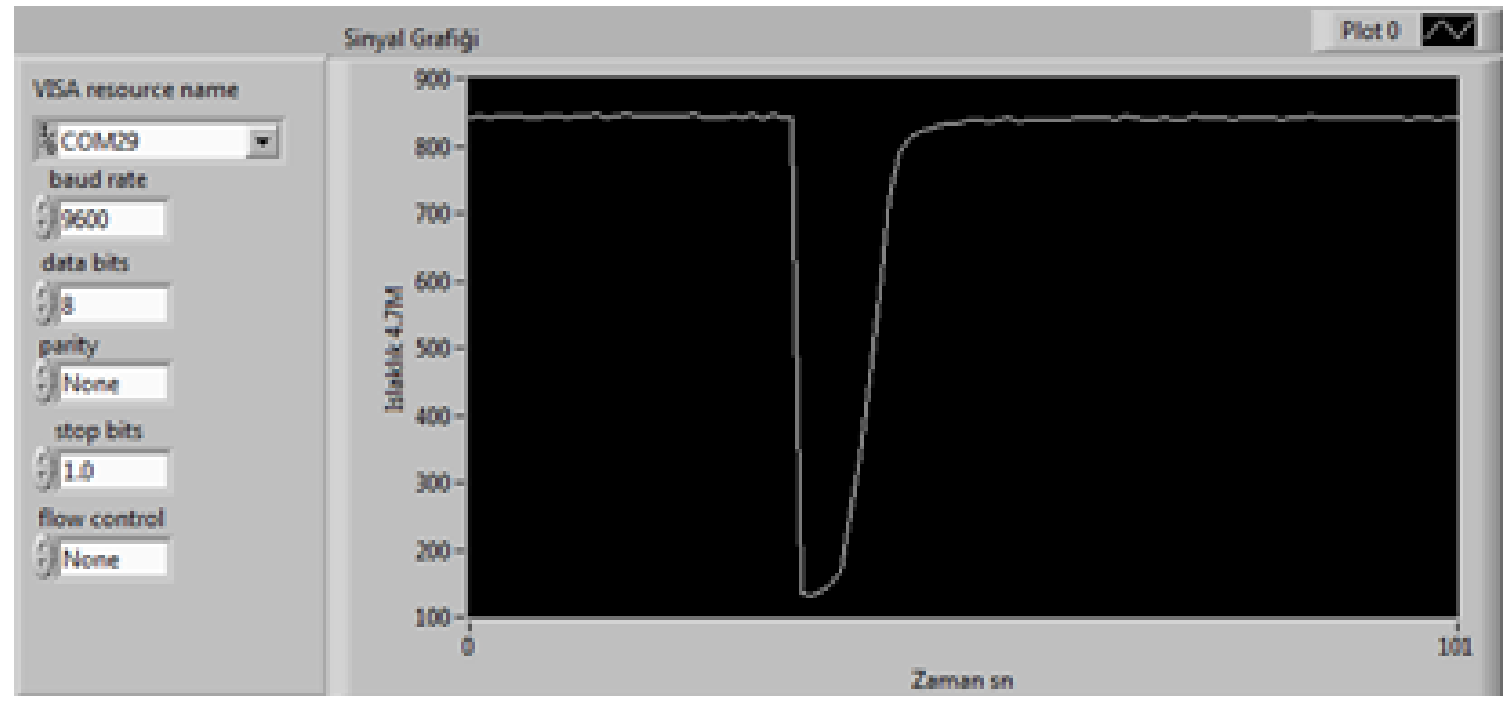

Şekil 6. 4,7 M $\Omega$ ' luk gerilim bölücü ile ıslaklık okuma

Oda ünitesi ile mobil ölçüm ünitesi arasındaki haberleşme bluetooth modüller kullanılarak yapılmıştır. Belirli aralıklarla sıcaklık ve ıslaklık verisi oda ünitesine gönderilmektedir. Bluetooth eşleşmesi sağlandıktan sonra veri iletimi tek yönlü olarak mobil ölçüm ünitesinden oda ünitesine doğru sağlanmaktadır(unicast). Sıcaklık ve ıslaklık verisi çerçeve olarak 10 byte uzunluğundadır. Labview programı üzerinden veri alınarak tespit edilmiştir. Veri alımı için seri haberleşme portları kullanılmaktadır. Mobil ölçüm ünitesinde Atmega328 mikrodenetleyicisi kullanılmıştır

Ünitenin şarj edilebilmesi amacıyla alt ve üstüne dect şarj ünitelerine takılabilecek şekilde kutuplar yerleştirilmiştir. Ünite 3,7 V lityum-polimer pil ile çalışmaktadır. Üniteye gerektiğinde hareket ile uyarı verebilmesi amacıyla titreşim motoru entegre edilmiştir. Mobil ölçüm ünitesi Şekil 7'de gösterilmiştir.

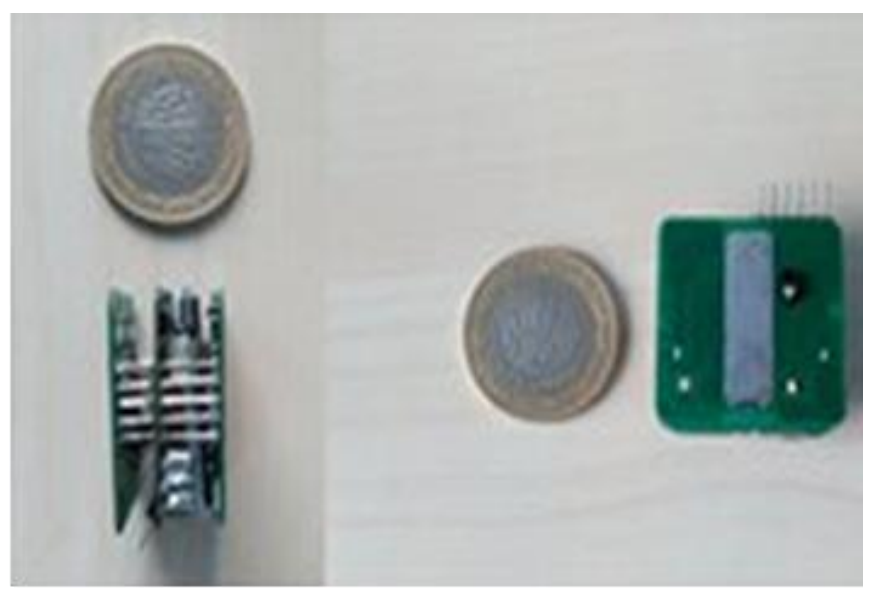

Şekil 7. Mobil ölçüm ünitesi donanımı

\section{Oda Ünitesinin Donanımı}

Oda ünitesi enerjisini direkt olarak şehir şebekesinden alabilmektedir. Alternatif akım doğru akım dönüşümünü kendi içerisinde sağlamaktadır. Alınan veriler oda ünitesi kullanılarak 128x64 grafik LCD üzerinden takip edilebilmektedir. Mobil Ölçüm ünitesiyle haberleşebilmesi amacıyla BLE 4.0 haberleşme özelliği eklenmiştir. Oda ünitesi ethernet ve wi-fi haberleşme yapabilmektedir. İnternet üzerinden takip edilebilmektedir. Üniteye ait prototipin görüntüsü Şekil 8'de gösterilmiştir.

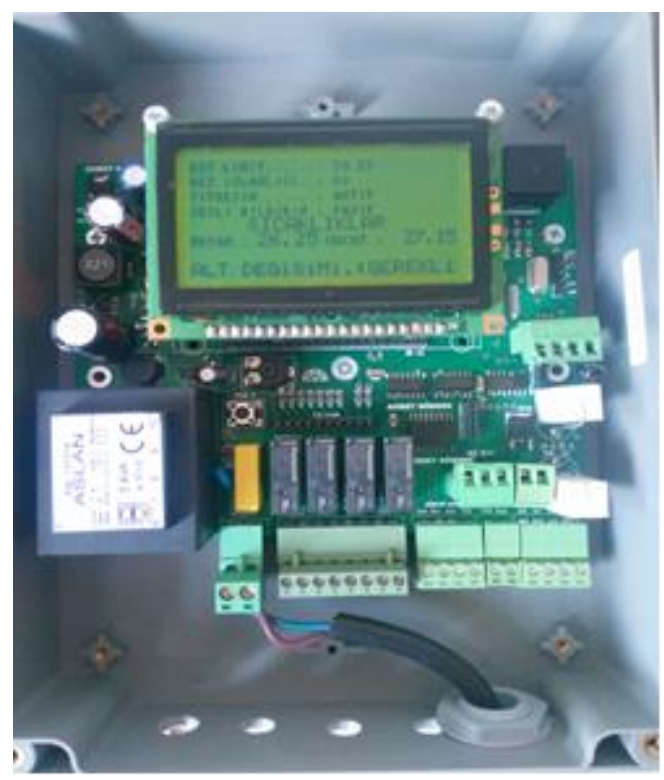

Şekil 8. Oda Ünitesi Prototipi 


\section{Mobil Takip Ünitesinin Donanımı}

Mobil takip ünitesi, android işletim sistemi tabanlı olarak hazırlanan uygulamayı çalıştırabilecek taşınabilir cihazdır. Kablosuz bağlantı üzerinden verileri oda ünitesinden alabilecektir. Aldığı verilere göre değerlendirmeler yapmaktadır. Bu ünite aynı zamanda sesli ışıklı ve titreşimli uyarı verebilmektedir.

\section{İlk Örnek Yazılımı}

\section{Mobil Ölçüm Ünitesi Yazılımı}

Kablosuz algılayıcı ünitenin algıladığı sıcaklık ve alt ıslaklığı verilerini oda ünitesine göndermesini sağlayacak yazılımdır. Mobil ölçüm ünitesi içerisinde Atmega 328 denetleyici kullanılmıştır. Arduino IDE programında yazılımı gerçekleştirilmiştir. Programın denemeleri sırasında alınan ekran görüntüsü Şekil 9' da gösterilmiştir. HM 10 BLE 4.0 modül devreye entegre edilmiştir.

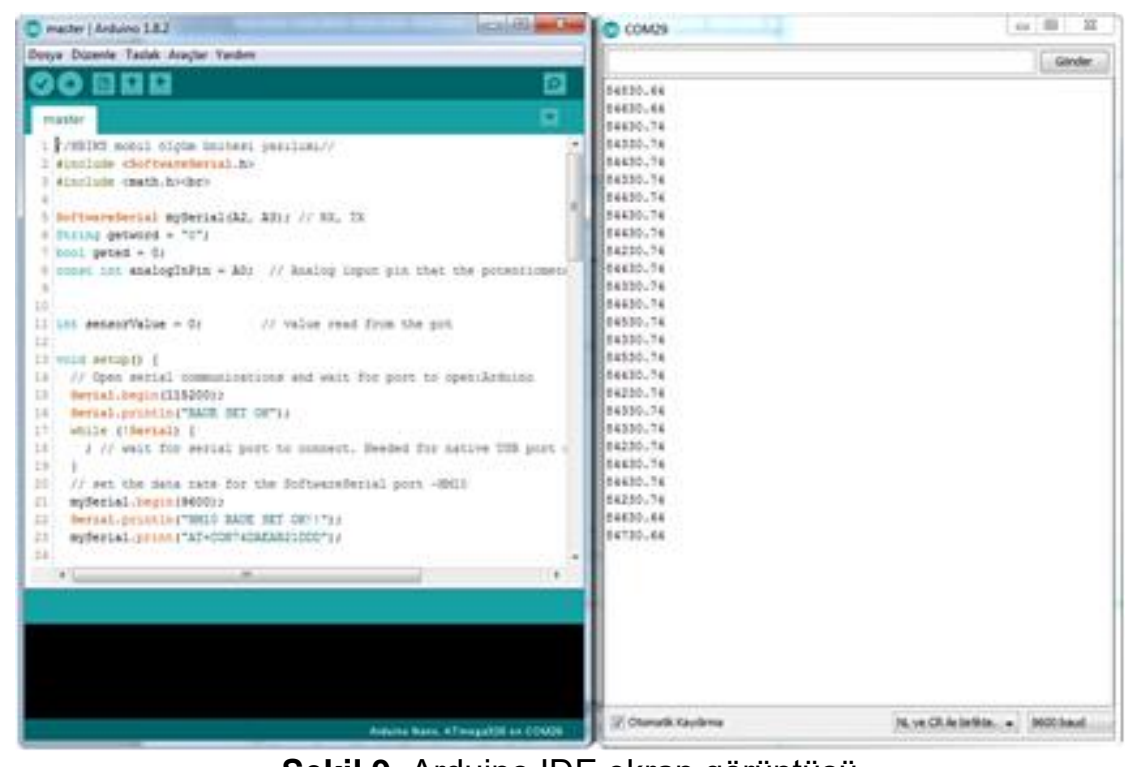

Şekil 9. Arduino IDE ekran görüntüsü

\section{Oda Ünitesi Yazılımı}

Oda ünitesi mobil ölçüm ünitesinin ölçtüğü verileri alarak yorumlamaktadır. Aynı zamanda bu verileri mobil takip ünitesine göndermektedir. Mobil ölçüm ünitesi ile arasındaki haberleşme Bluetooth 4.0 standardı ile sağlanmak- tadır. Oda ünitesinde düşük güç tüketimi zorunluluğu olmadığı için kapsama alanı daha geniş olan wireless haberleşme protokolleriyle mobil takip ünitesiyle iletişim kurabilir. Bunun yanında mobil takip yazılımı aracılığıyla veriler internet üzerinden de alınabilir. Oda ünitesine ait haberleşme şeması Şekil 10'da verilmiştir.
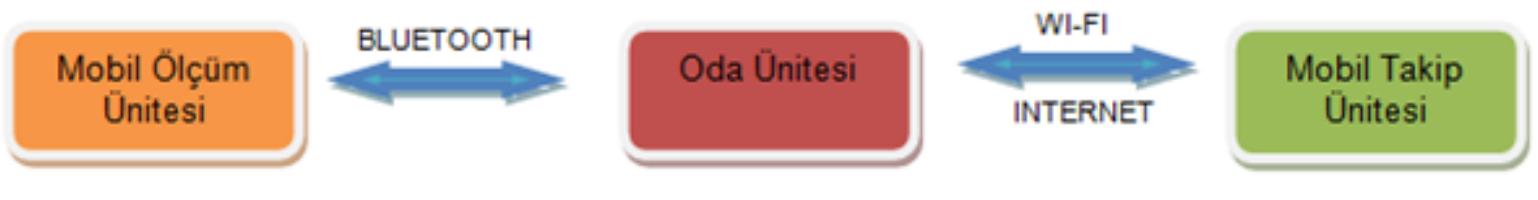

\section{Şekil 10. Oda Ünitesi Haberleşmesi}

Programlayıcı olarak Pickit-2 programlayıcısı kullanımıştır. Programa ait akış diyagramı Şekil 11'de gösterilmiştir. Mobil ölçüm ünitesinin Bluetooth modülü ile oda ünitesinin Bluetooth modülü arasında eşleşme otomatik olarak sağlanmaktadır. Daha sonra oda ünitesi alıcı konuma geçerek mobil ölçüm ünitesinin gönderdiği verileri almaktadır. Alınan veri değerlendirilmekte alarm seviyeleri ile kıyaslanarak alarm verilmesinin gerekli olup olmadığı tespit edilmektedir. Aynı zamanda alınan veriler mobil takip ünitesine de iletilmektedir. 


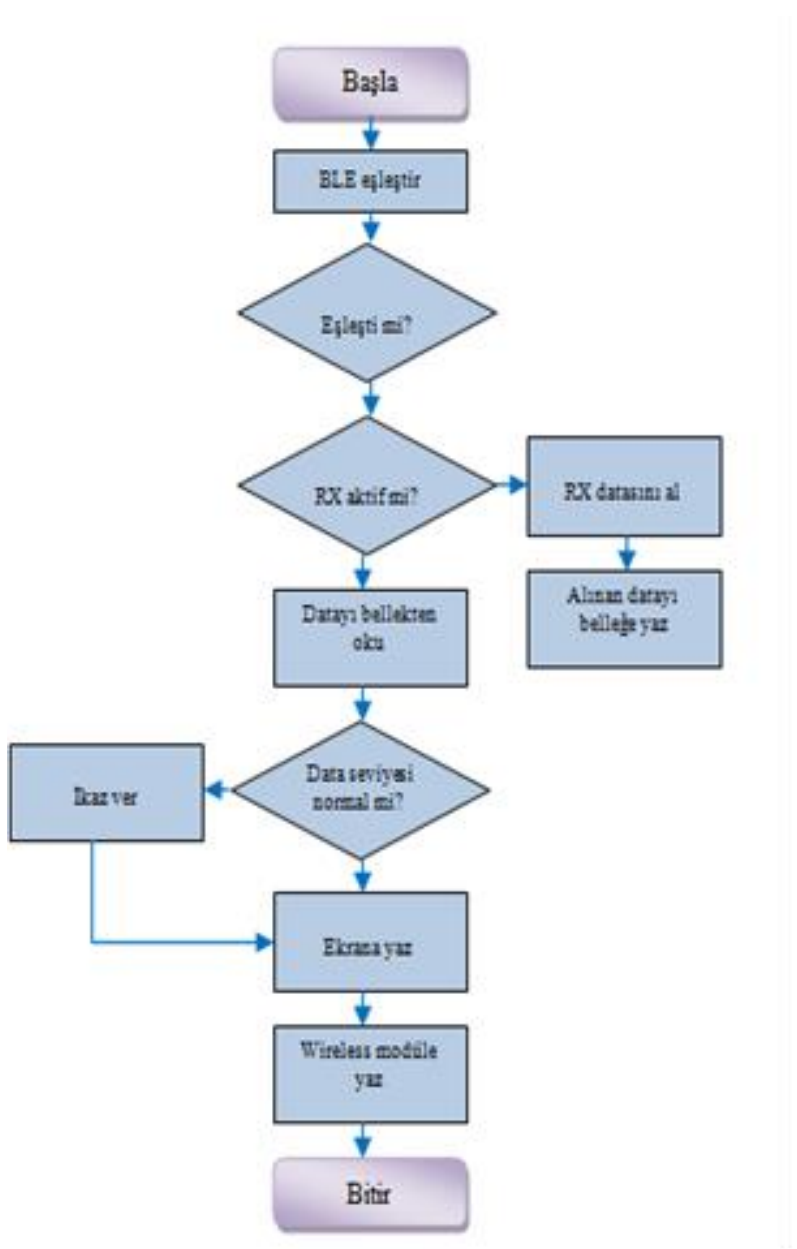

Şekil 11. Oda Ünitesi Genel akış Diyagramı

\section{Mobil Takip Ünitesi Yazılımı}

Mobil takip ünitesinde çalıştırılacak programın android işletim sistemine uyumlu olması düşünülmüştür. Açık kaynak kodlu olması ve geliştiricilere daha fazla imkan sunması nedeniyle android platformu tercih edilmiştir. Program Android Studio, tümleşik geliştirme ortamı kullanılarak hazırlanmıştır. Android uygulama marketlerinden dağıtımı da kolaylıkla yapılabilir. Kablosuz haberleşme ile oda ünitesinden alınan verileri işleyerek alarm durumunun belirlenmesini sağlar. Aynı zamanda raporlamanın yapılabilmesi için ölçülen değerleri kayıt altına alır. Mobil takip ünitesinde çalıştırılacak olan uygulamanın ekran görüntüsü Şekil 12'de gösterilmiştir.

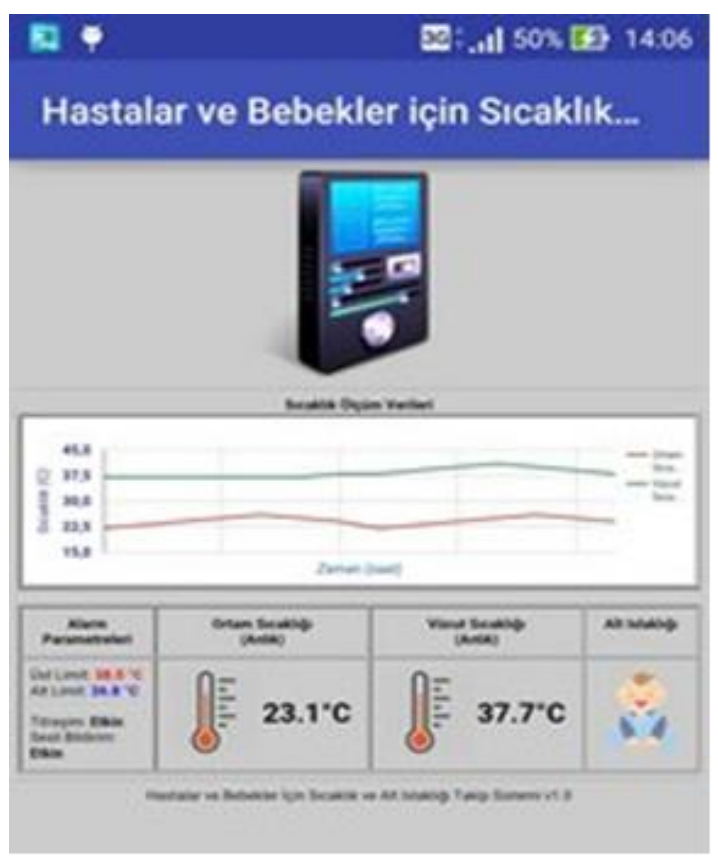

Şekil 12. Mobil Uygulama Ekran Görüntüsü 


\section{BULGULAR VE TARTIŞMA}

Gerçekleştirilen ilk örnek ile vücut sıcaklığı ve ıslaklık ölçümü yapılabilmektedir. Sistemin gerçek denekler üzerinde denenerek sonuçlarının sosyal yaşama katkılarının ölçülmesi ayrı bir araştırmanın konusudur. Alt değişim zamanının tespitinde kullanılacak ölçütlerden en önemlisi olan nem miktarının optimum seviyesinin tespit edilmesi için gerçek hastalarla tıp doktorlarının gözetiminde çalışılmalıdır. Sistem ayarlanabilir özelliğe sahip olduğundan üzerinde ilave bir değişiklik gerekli değildir. Eşik seviyelerinin ayarlanması mobil takip ünitesinden yapılabilmektedir. Tüm bunlar göz önüne alındığında geliştirilen ilk örneğin tıbbi denemelerin yapılabilmesi için yeterli donanım özelliklerine sahip olduğu anlaşımaktadir.

Kablosuz algılayıcı sistemlerin en önemli kısıtlaması enerji kaynağının ve işlemci gücünün yetersizliğidir. Kablosuz ve mobil cihazların en temel enerji kaynağını batarya teşkil eder. Batarya ömrünün kimyasal olarak uzatılması oldukça güçtür. Yine aynı şekilde daha uzun süreli pil ömrü için fiziksel olarak daha büyük batarya kullanımı gerekmektedir. Batarya boyutunun büyümesi taşınabilirlik anlamında problemler meydana getirir. Hem bataryanın fiziksel olarak küçültülmesi hem de kullanım süresinin uzatılabilmesi için haberleşme süresinin kısaltılması ve sinyal gönderim gücünün düşürülmesi planlanmış ve bu şekilde haberleşmeden taviz vermeksizin çalışma süresinin uzatılabildiği yapılan denemeler sonucunda ortaya konmuştur.

\section{SONUÇ VE DEĞERLENDIRME}

Proje kapsamında HBIKS elektronik sisteminin üretilmesi ile biyomedikal alanında;

- Cilt hastalıklarının oluşmasının engellenmesinde ve tedavi sırasında alt değişim zamanını doğru olarak tespit edebilen,

- Yatan hastalarda, özellikle felçli hastalar gibi sürekli bakıma muhtaç olanlarda hem bakan kişiyi çok sık alt kontrolünden kurtaran hem de hastanın rahatsız edilmemesini sağlayan,

- Hastanelerde ve evlerde hastalara bakan kişilerin işlerini kolaylaştıran,

- Çocuklarda alta kaçırma hastalığının tedavisinde titreşimli alarm sistemi olarak ta kullanılabilen(sadece mobil ölçüm ünitesi kullanılabilir),

- Vücut sağlık parametrelerinden biri olan sıcaklığın düzenli takibi ile ani ateş yükselmeleri görülen hastalarda erken müdahale edebilme imkânı veren bir cihaz kazanılmıştır.

Teknik Bilimler alanında;
Bluetooth ve Wi-Fi haberleşme teknolojileri kullanılarak haberleşme sinyalleri ve protokolleri hakkında deneyim elde edilmiştir.

Mobil ölçüm modülünün geliştirilmesiyle farklı teknik alanlarda veri alımı ve aktarımını gerçekleştirebilecek bir sistemin ana hatları oluşturulmuştur.

\section{TEŞEKKÜR}

Bu çalışma 0367-NAP-016 numaralı NAP projesi olarak Mehmet Akif Ersoy Üniversitesi BAP Koordinatörlüğ̈̈nce desteklenmiştir. Desteklerinden dolayı Mehmet Akif Ersoy Üniversitesi Rektörlüğü ve BAP koordinatörlügüne teşekkür ederiz.

\section{KAYNAKLAR}

Atar, M., Sancaktutar, A. A. (2011). Non-Pharmocological Treatment of Nocturnal Enuresis. Turkish Urology Seminars 2: 50-54.

Chien, C. N., Hsu, H-W., Jang, J. K., Rau, C. L., Jaw, F. S. (2005). Microcontroller-Based Wireless Recorder for Biomedical Signals. 2005 IEEE Engineering in Medicine and Biology 27th Annual Conference : 5179-5181.

Cosmanescu, A., Miller, B., Magno, T., Assad,A., Kremenic, I. (2006). Design and Implementation of a Wireless (Bluetooth) Four Channel Bio-Instrumentation Amplifier and Digital Data Acquisition Device with User-Selectable Gain, Frequency, and Driven Reference. 2006 International Conference of the IEEE Engineering in Medicine and Biology : 2053-2056.

Çetin, G. D., Bayılmış, C., Kaçar, S., Kırbaş, İ. (2012). Application of an on-line medical monitoring system. Signal Processing and Communications Applications Conference (SIU).

Eriş, Ö., Korkmaz, H., Toker, K., Buldu, A. (2010). İnternet Üzerinden Hasta Takibi Amaçlı PIC Mikrodenetleyici Tabanlı Kablosuz Pals-Oksimetre Ölçme Sistemi Tasarımı ve LabVIEW Uygulaması.VII. Ulusal Tıp Bilişimi Kongresi Bildirileri : $16-25$.

Ertürk, U.,Filiz,K.(2017). http://www.ayhankargin.com/aymuh/Bluetooth/bluetooth_1.pdf(28.07.2017)

Fazel-Rezai, R., Pauls, M., Slawinski, D. (2007).A Low-Cost Biomedical Signal Transceiver Based on a Bluetooth Wireless System. Annual International Conference of the IEEE Engineering in Medicine and Biology : 5711-5714.

Figueredo, M. V. M., Dias, J. (2004). Mobile Telemedicine System for Home Care and Patient Monitoring. Annual International Conference of the IEEE Engineering in Medicine and Biology Society Conference 5: 3387-3390.

Işık, A. H., Güler, İ.(2010). Teletıpta Mobil Uygulama Çalışması ve Mobil İletişim Teknolojilerinin Analizi, Bilişim Teknolojileri Dergisi 3: 1-10.

Işık, A. H., Şener, M. U., Güler, İ. (2013). A Low Cost Mobile Adaptive Tracking System for Chronic Pulmonary Patients in Home Environment. Telemedicine Journal and E-Health 19:24-30

Kara, A., Ortac, E., Hapa, A., Ocal, S.,Topeli, A.( 2015).Dermatological Problems and Dermatology Consultations in 
Intensive Care Units. Turkish Journal of Medical and Surgical Intensive Care 6: 1-3.

Kirbaş, İ., Bayılmış, C., Kaçar, S., Çankaya, İ.( 2010). İnkübatörlerin Uzaktan İzlenmesi ve Kontrolü İçin Yeni Bir Teknoloji: Kablosuz Algılayıcı Ağlar.Tıp Teknolojileri Ulusal Kongresi: 49-53.

Kumar, A.,Fazlur, R.(2006). Wireless Health Alert and Monitoring System. ICBPE 2006 - Proceedings of the 2006 International Conference on Biomedical and Pharmaceutical Engineering: 241-45.

Kyriacou, E.,Pavlopoulos, S.,Koutsouris, D.,Andreou, A.S.,Pattichis, C.,Schizas, C.(2001).Multipurpose Health Care Telemedicine System. Conference Proceedings of the 23rd Annual International Conference of the IEEE Engineering in Medicine and Biology Society: 3544-3547.
Moron, M. J., Eduardo C., Luque, R., Gázquez, J. A.(2005).A Wireless Monitoring System for Pulse-Oximetry Sensors. 2005 Systems Communications (ICW'05, ICHSN'05, ICMCS'05, SENET'05) : 79-84.

Navarro, E. A. V., Mas, J. R., Navajas, J. F., Alcega, C., P.(2005). N-Health System. EUROCON 2005: 1332-1335.

Oweis, R. J., Barhoum, A. (2007). PIC Microcontroller-Based RF Wireless ECG Monitoring System.Journal of Medical Engineering \& Technology 31: 410-418.

Önder, M., Adışen, E., Velagiç, Z. (2007). Diaper Dermatit. Cocuk Sagligi ve Hastaliklari Dergisi 50: 129-135.

Toral, T. R., Palomares, R. A., Iturriaga, M. C., Yuhsi, T.(2007).Vital Signs Monitoring through Internet.17th International Conference on Electronics, Communications and Computers, CONIELECOMP'07.. 